Article

\title{
Analysis of the Learning Effectiveness of the STEAM-6E Special Course-A Case Study about the Creative Design of IoT Assistant Devices for the Elderly
}

\author{
Chih-Chao Chung ${ }^{1}$, Chien-Linag Lin ${ }^{2}$ and Shi-Jer Lou ${ }^{3, *}$ (D) \\ 1 Fortune Institute of Technology, Kaohsiung 83160, Taiwan; t03050@fotech.edu.tw \\ 2 National Cheng Chi University, Taipei 11605, Taiwan; lin.chienliang@gmail.com \\ 3 National Pingtung University of Science and Technology, Pingtung 91201, Taiwan \\ * Correspondence: 9915916@gmail.com
}

Received: 19 July 2018; Accepted: 24 August 2018; Published: 27 August 2018

check for updates

\begin{abstract}
This study developed a STEAM (Science, Technology, Engineering, Art, and Math)-6E (Engage, Explore, Explain, Extend, Enrich, Evaluate; 6E Learning by Design) special course based on the theme of creative design of IoT (Internet of Things) assistant devices for the elderly and investigated the impact of this course on students' learning effectiveness. It invited eight experts and scholars for focus interviews, jointly developed the STEAM-6E special course, designed teaching activities around the theme of creative design of IoT assistant devices for the elderly, and created a learning effectiveness scale. Furthermore, it selected 46 students majoring in nursing in a vocational and technological college as its subjects and distributed copies of a questionnaire among them to explore learning effectiveness. This study reached the following conclusions. The STEAM-6E special course on the creative design of IoT assistant devices for the elderly included three dimensions, that is, the STEAM course, $6 \mathrm{E}$ teaching, and the acquisition of professional knowledge, as well as 17 competence indicators. The nursing students affirmed the learning outcome in the STEAM-6E course, the $6 \mathrm{E}$ teaching model, and thematic knowledge after attending the STEAM-6E course. The hands-on activities of the STEAM-6E special course could guide students to learn key points step by step. The STEAM-6E special course can strengthen students' abilities to integrate STEAM knowledge and improve their learning effectiveness in each discipline. The STEAM-6E special course for the elderly improved the cooperative learning, professional knowledge, and confidence of the students. In light of these conclusions, this study developed a teaching model for the STEAM-6E special course on the creative design of IoT assistant devices for the elderly and proposed several suggestions for curriculum planning and the implementation of a STEAM-6E special course.
\end{abstract}

Keywords: STEAM; 6E; Creative Design; Internet of Things; Assistant Devices

\section{Introduction}

With advances in medical treatments, public health, and science and technology, individuals can usually now live to be seventy years old. Although longevity is a common desire in humans, the development of an aging population also leads to health-related issues such as chronic diseases and physical malfunctions of the elderly. Due to their lack of self-care ability, the number of elderly people requiring special care is increasing [1]. Therefore, how to establish a comprehensive, long-term care mechanism and how to delay disabilities in elderly people have become significant issues in today's society, thereby highlighting the necessity to integrate emerging technologies in the development of assistant devices for the elderly. 
However, a declining birth rate accompanies this aging society. Thus, higher education in various countries has begun to emphasize interdisciplinary learning and strengthening interdisciplinary thinking and sources of creativity to cultivate the talents required for future advances [2]. As a result, this has become a topic of concern in recent years in the education sector in advanced countries such as the United States as they develop Science, Technology, Engineering, Art and Math (STEAM) courses. A STEAM course consists of five disciplines-science, technology, engineering, art, and mathematics-and provides learning scenarios that are complex yet close to reality to help students integrate conceptual and procedural knowledge in engineering design and sci-tech exploration, which cultivates students' problem-solving and creative design abilities [3]. Its main educational purpose is to guide students to integrate interdisciplinary knowledge, raise their interest in participating in STEAM learning, and develop their employability in STEAM fields [4]. Previous STEAM studies, such as Debeş [5], have indicated that STEAM seminars have resulted in positive changes to teachers' mathematics teaching self-efficacy strategies. Kim and Bolger discussed the influence of STEAM lesson plans on elementary preservice teachers' attitudes toward STEAM [6]. In STEAM education, Bahrum, Wahid and Ibrahim indicated that the main thing to keep in mind in implementing STEAM education in Malaysia is to increase students' interest and teachers' awareness of STEAM education [7].

Asking questions is the starting point for students to form creativity. It inspires their desire to continue to explore by answering the questions they raise. Therefore, it is of crucial importance to train students to ask questions and solve problems in order to cultivate creativity and practical ability [8]. Today, problem-based learning (PBL) has been widely applied to different fields and educational backgrounds. For instance, PBL has been adopted to allow students to learn a subject by trying to answer open-ended questions to improve their critical thinking and problem-solving ability [9]. Meanwhile, in PBL, students learn in a group. By defining and executing tasks and communicating with team members, they acquire knowledge to learn basic problem-solving abilities, a key skill required in nearly all working environments [9]).

In recent years, ITEEA (International Technology and Engineering Educators Association, ITEEA) has introduced 6E Learning by Design to guide students through interdisciplinary and integrative learning and allow them to gradually deepen their learning through hands-on processes and making products [10].

This study planned the STEAM-6E special course titled the Creative Design of IoT Assistant Devices for the Elderly (STEAM-6E special course), guided students to understand the principles and applications of IoT emerging technologies, and applied the $6 \mathrm{E}$ mode to thinking, ideation, design, revision, and practice. Based on long-term nursing-related courses in the nursing department of a vocational college, it combined concepts in electricity and mechanics and guided students to learn the principles and applications of IoT-related emerging technologies. Moreover, it utilized STEAM integrative thinking in course planning and allowed students to apply scientific knowledge, engineering technologies, aesthetic creation, and mathematical computing abilities to solve problems and verify knowledge in order to achieve their teaching goals. The purposes of this study were as follows:

(1) Exploring the key teaching points of the STEAM-6E special course;

(2) Investigating the learning effectiveness of the students in the STEAM-6E special course; and

(3) Analyzing the learning progress of the students in the STEAM-6E special course.

\section{Literature Review}

\subsection{Scientific Assistant Devices for the Elderly}

With the advent of our aging society, countries have begun actively promoting relevant care services and developing relevant information and communication technologies (ICT) related to assistant devices for the elderly to meet the future needs of individuals [11]. In accordance with the report of the International Federation on Aging in 2012, the applications of science and technology 
in long-term care include seven fields: optimal drug treatment, remote patient monitoring, assistant device technology, remote training and supervision, disease management, cognition and fitness assessment, and social networking. Faced with the influences of aging and a low birth rate, Taiwan has begun to actively develop remote electronic care services [12].

Elderly people usually prefer to stay at home rather than live in care facilities. As a result, emphasis is being placed on home safety assistant devices. These assistant and wearable devices can improve the safety of the elderly living at home [13]. In addition, in terms of remote care, as various smart devices become popular and more refined, a remote health management and care monitoring system that can be used anytime and anywhere can allow family members or caregivers to obtain real-time images via a remotely controlled camera or get information from other pre-installed sensors for remote and real-time monitoring, reminders, and warnings to reduce the burden of caregivers and achieve greater care efficacy [11].

Hence, through the creative design and production of assistant devices for the elderly, this study intended to guide learners to create and acquire practical experience in integrating scientific knowledge, production techniques, engineering construction, and innovative ideas related to the care of the elderly and the design of assistant devices.

\subsection{Internet of Things (IoT)}

IoT stands for smart devices that can generate data by interacting and communicating with other devices, objects, environments, and infrastructure and then translate these data into practical behaviors to facilitate human life $[14,15]$. Thanks to its high degree of intelligence and diversity, IoT is widely used in various fields. Furthermore, in the current information era, IoT forges relationships between people and objects and among objects [16]. Recently, IoT has been used in smart city campaigns around the world with new applications. It offers remote monitoring and equipment management functions and creates new insights and actionable messages from large amounts of data. In particular, after sensors (e.g., Radio Frequency IDentification, infrared rays, Global Positioning System, and laser scanners) are installed, the information received by those sensors can be exchanged and connected to the Internet to create intelligent identification, positioning, tracking, monitoring, and management $[17,18]$.

Therefore, based on IoT, this study aimed to guide learners to creatively design and make assistant devices for the elderly, as well as gain practical experience in integrating IoT emerging technology-related knowledge, production techniques, mathematical calculation, engineering construction, and innovative ideas.

\subsection{STEAM}

STEAM teaching adopts a mutually integrative teaching method and focuses on guiding students to actively construct relationships among science, technology, engineering, and mathematics. In addition to integrative thinking and interdisciplinary learning, the essence of STEAM teaching emphasizes the combination of theory with real situations and enables learners to understand and apply integrated knowledge at any time [19].

The Rhode Island School of Design assisted in the development of a STEAM teaching plan but did not clearly define STEAM teaching. Scholars from different countries have varied interpretations. Some have explained it from the perspectives of creation and integration, while others have described it from a student-centered viewpoint [20]. STEAM is an interdisciplinary teaching method that combines science, technology, engineering, art, and mathematics. With basic mathematical knowledge, students are expected to conduct engineering and art design and learn the connotations of science and technology [21]. To date, STEAM has been widely applied to study improvements in teaching [7], students' education strategies, and practical applications for students [22]. A summary of the research topic and methodology can be found in Table 1.

With respect to the STEAM teaching method of this study, the course was designed from the perspectives of creation and student orientation. This study guided learners to creatively design 
and produce IoT assistant devices for the elderly and gain practical experience in integrating scientific knowledge, production techniques, mathematical calculations, engineering construction, and innovative ideas.

Table 1. Review of the Discussion Topic and Methodology.

\begin{tabular}{lll}
\hline Author & Discussion Topic & Methodology \\
\hline $\begin{array}{l}\text { Bahrum, Wahid and } \\
\text { Ibrahim [7] }\end{array}$ & Educational policy, Teaching method improvement & Literature review \\
\hline Choi, Lim and Son [21] & Middle School Students' education in South Korea & Survey \\
\hline Ko [20] & $\begin{array}{l}\text { Practical Application in Electric Steam Iron by } \\
\text { College Students }\end{array}$ & Experimental Design \\
\hline Park et al. [23] & $\begin{array}{l}\text { Teachers' Perceptions and Practices, Teachers of } \\
\text { Science, Technology, Engineering, Art \& Math } \\
\text { (STEAM) education }\end{array}$ & Survey \\
\hline Debeş [5] & Effects of STEAM Education Seminars on Teachers & Experimental Design \\
\hline Kim and Bolger [6] & $\begin{array}{l}\text { South Korean teachers integrate STEAM pedagogy } \\
\text { through the development of a curriculum plan }\end{array}$ & Survey \\
\hline Chien and Chu [22] & $\begin{array}{l}\text { Students on a 3D-Printing STEAM Engineering } \\
\text { Design Curriculum }\end{array}$ & Experimental Design \\
\hline
\end{tabular}

\section{4. $6 E$}

The American Science Curriculum Improvement Study (SCIS) proposed a basic teaching model in 1960. It put forward a set of teaching procedures for science and technology education that included three steps: exploration, invention, and discovery. In the field of science and technology education, Barry modified the 5E teaching circle and proposed a student-centered $6 \mathrm{E}$ teaching model in order to strengthen the design and exploration abilities in STEAM education [24]. The six procedures are the following:

(1) Engage: A teacher confirms appropriate course contents, utilizes handouts and teaching aids to arouse students' curiosity, interest, and engagement, and defines the concepts, objectives, and importance of a unit. The teacher can present finished products first in order to make students think that they can also accomplish the task and to stimulate their interest.

(2) Explore: Students are offered opportunities to construct their own learning experience. Teachers use knowledge in a variety of fields to design simple questions for students to think about, make students familiar with the use of teaching materials, and encourage students to apply the basic knowledge learned and accumulate experience. For example, students are asked to form groups, discuss ways to use teaching materials, exchange opinions, and deepen basic understanding.

(3) Explain: Students explain and improve on what they have learned. Teachers need to organize systematic and structured cognition of students at this stage. Therefore, teachers are expected to point out mistakes that students have made and ask students to review the key points of the teaching materials. Teachers can ask students questions to determine their mastery of a course. In the meantime, via questions and answers, students are guided to discuss and clarify concepts that they are unsure about.

(4) Engineer/Extend/Elaborate: Students apply the basic knowledge learned, materials, and tools to create a prototype that can solve the current problem. By integrating knowledge and abilities, students can gain a deeper understanding of a problem. Teachers can design a problem to be solved based on reality. Moreover, students must integrate the knowledge and skills learned in order to solve the problem.

(5) Enrich: To explore more deeply and reach a broader application of the knowledge learned, students are asked to perform exercises in different dimensions to apply what they have learned to solve problems that are more complex. 
(6) Evaluate: Teachers and students shall understand the learning outcomes. Teachers set test standards and use test tools to measure students' learning needs and deficiencies.

Each cycle of the $6 \mathrm{E}$ teaching model represents a complete unit. Because students must continue thinking during the process, these teaching procedures are suitable for STEAM teaching. This study employed the $6 \mathrm{E}$ teaching model to conduct the STEAM special course and guide learners to gradually complete the creative design and production of IoT assistant devices for the elderly, acquire more specific IoT knowledge, gain the ability to design assistant devices for the elderly, and utilize STEAM integrative knowledge and abilities.

\section{Research Design}

In line with our purposes and the literature review, this study developed the STEAM-6E course and analyzed the learning effectiveness of the students. The relevant research subjects, methods, and tools are described below.

\subsection{Development of the STEAM-6E Course}

Concerning the development of the STEAM-6E course, this study adopted focus group interviews [25] and invited experts in the fields of creative design, STEAM, health care, elderly care, design of assistant devices, IoT, and smart home appliances to plan the STEAM special course. The research team of this study interviewed the experts to summarize and analyze their suggestions regarding the objectives and contents in order to develop and gradually revise the STEAM-6E special course on the creative design of IoT assistant devices for the elderly and to provide a basis for the development of the learning effectiveness questionnaire.

\subsection{Learning Effectiveness of the STEAM-6E Course}

In terms of the learning outcomes of the STEAM-6E course, this study employed quasi-experimental research, mixing both quantity and quality. The research subjects and tools are described as follows.

(1) Research subjects

This study adopted purposive sampling and considered 46 students aged between 19 and 20 years old in the Department of Nursing at a vocational college in southern Taiwan as its subjects: 10 were males, and 36 were females. None had taken a STEAM-related course. This study used group learning to conduct the course. The students were divided into 10 groups, each of which had four to five students. The course lasted 15 weeks. Each week, the students received a 3-hour class in the STEAM-6E course on "creative design of IoT assistant devices for the elderly". This study then analyzed the influence of the course on the learning effectiveness of the students.

(2) Quantitative research tools

With respect to quantitative analysis, the questionnaire method was used, with copies of a questionnaire distributed to the respondents. One sample t-test was carried out to understand the influence of STEAM-6E on the learning effectiveness of the subjects. This study developed the "Questionnaire on the Learning Effectiveness of Students Attending the STEAM-6E Course", which included a total of 17 questions under three headings: "STEAM course", "6E teaching", and "professional knowledge". Regarding the reliability of the scale, through purposive sampling, 103 respondents were selected to receive the pretest. Copies of the questionnaire were recovered for item analysis, and inappropriate items were deleted. The principal component analytical method was coupled with Varimax to perform an orthogonal rotation. The factor loadings of "STEAM course", "6E teaching", and "professional knowledge" in the Questionnaire on the Learning Effectiveness of Students Attending the STEAM-6E Course are 0.76-0.84, 0.79-0.88, and 0.78-0.91, respectively. Their Cronbach's $\alpha$ values are $0.92,0.93$, and 0.95 , respectively, indicating that the scale has good reliability. 
(3) Qualitative research tool

From a qualitative analysis perspective, this study used document analysis to understand the learning effectiveness of students attending the STEAM-6E course. This study built a mobile learning platform as a context for students to engage in cooperative learning. Moreover, it collected file data on learning interaction among students, task-learning feedback, written reports, activity photos and records, and group works as the basis for the qualitative analysis of students' learning effectiveness. For the coding principles of the file data of the 10 groups of students, please refer to Example S0203. Here, $\mathrm{S}$ indicates students' text information, while 02 is the second group and 03 is the third student.

\subsection{Construction of the STEAM-6E Teaching Model}

The development of the STEAM- 6 E course in this study included course planning, the determination of the learning objectives, analysis, and assessment of STEAM concepts, and the construction of the STEAM-6E teaching model, as described below.

(1) Course planning and determination of learning objectives

This study adopted focus group interviews and invited eight experts from universities and companies in the fields of engineering education, creative design, STEAM, long-term care, design of assistant devices, IoT, artificial intelligence, and smart home appliances. All of the experts had more than 13 years of experience. There were two university professors, two associate professors, and four executives in industries who jointly planned the STEAM-6E special course. This study discussed, analyzed, and summarized the opinions and suggestions of the experts to develop the STEAM-6E special course on the creative design of IoT assistant devices for the elderly and to determine the course objectives and contents.

Based on the discussion and analysis of focus group interviews with the experts, the objectives of the STEAM-6E special course on the creative design of IoT assistant devices for the elderly included three dimensions - the STEAM course, the $6 \mathrm{E}$ teaching model, thematic knowledge - and 17 objectives.

(2) Analysis of reliability and validity of STEAM-based design

In terms of the analysis of the reliability and validity of the STEAM-6E special course on the creative design of IoT assistant devices for the elderly, in order to enhance the accuracy of the question design of the scale, the eight experts inspected the rationality of the content design and objectives among the three dimensions step by step. Moreover, they checked the design and completion of each question and assessed the accuracy of each question to strengthen the overall reliability of the questions and the accuracy of experts' validity and to reduce errors in subsequent measurements.

\section{(3) Analysis and assessment of STEAM concepts}

This study began by analyzing the subjects on physical fitness and exercise, living assistant devices, health promotion, and long-term care practices related to the elderly in the department of nursing at a vocational school. Coupled with discussions with teachers and experts in STEAM, it proposed the knowledge structure of the STEAM-6E special course, as shown in Table 2. The theme was the creative design of IoT assistant devices for the elderly. This study asked students to integrate IoT technologies, utilized the STEAM integrative learning approach and guided students to integrate the knowledge and contents of a long-term care practice course with routine life experiences and observations to complete the course tasks. 
Table 2. Integrating Internet of Things (IoT) technologies and STEAM concepts in the creative design of IoT assistant devices for the elderly.

\begin{tabular}{cl}
\hline STEAM & \multicolumn{1}{c}{ Concepts } \\
\hline Science & $\begin{array}{l}\text { Newton's Second Law of Motion, energy and force, visual space, basic electricity, } \\
\text { conservation and conversion of energy, static balance, dynamic balance, } \\
\text { stress-strain analysis, and center of gravity }\end{array}$ \\
\hline Technology & $\begin{array}{l}\text { Servo motors, analog output, assembly ability, use of hand tools or machines and } \\
\text { tools, creative design, product testing and correction, energy and power, 2D } \\
\text { computer graphics, and 3D computer graphics }\end{array}$ \\
\hline Engineering & $\begin{array}{l}\text { Arduino programming, computer graphics, material use, product design, } \\
\text { structural design, engineering design, truss assembly, test implementation and } \\
\text { assessment, problem determination and resolution }\end{array}$ \\
\hline Art & $\begin{array}{l}\text { Structural aesthetics, hand tooling operational capacity, handicraft ability, } \\
\text { material assessment and application }\end{array}$ \\
\hline Math & $\begin{array}{l}\text { Digital output, rotational speed operation, power conversion, basic measurement, } \\
\text { angle conversion, geometric concepts, trigonometric functions, algebra, and } \\
\text { analytic geometry }\end{array}$ \\
\hline
\end{tabular}

\section{(4) STEAM-6E teaching procedures}

The teaching activities in this study were developed in conformity with the $6 \mathrm{E}$ model, and the design of the teaching plan also referred to the teaching objectives. This study integrated STEAM knowledge, key skills in long-term care courses, and cooperative learning strategies. Figure 1 shows the procedures of the STEAM-6E special course related to the creative design of IoT assistant devices for the elderly. In line with the course objectives, key points for the teachers and students were set to confirm the feasibility and effectiveness of the course and verify compliance with STEAM knowledge, concepts, and capabilities. In addition, in the $6 \mathrm{E}$ procedures, the students were expected to complete the tasks at each stage and make the products mostly by themselves, while the teachers undertook guidance and explanation. 


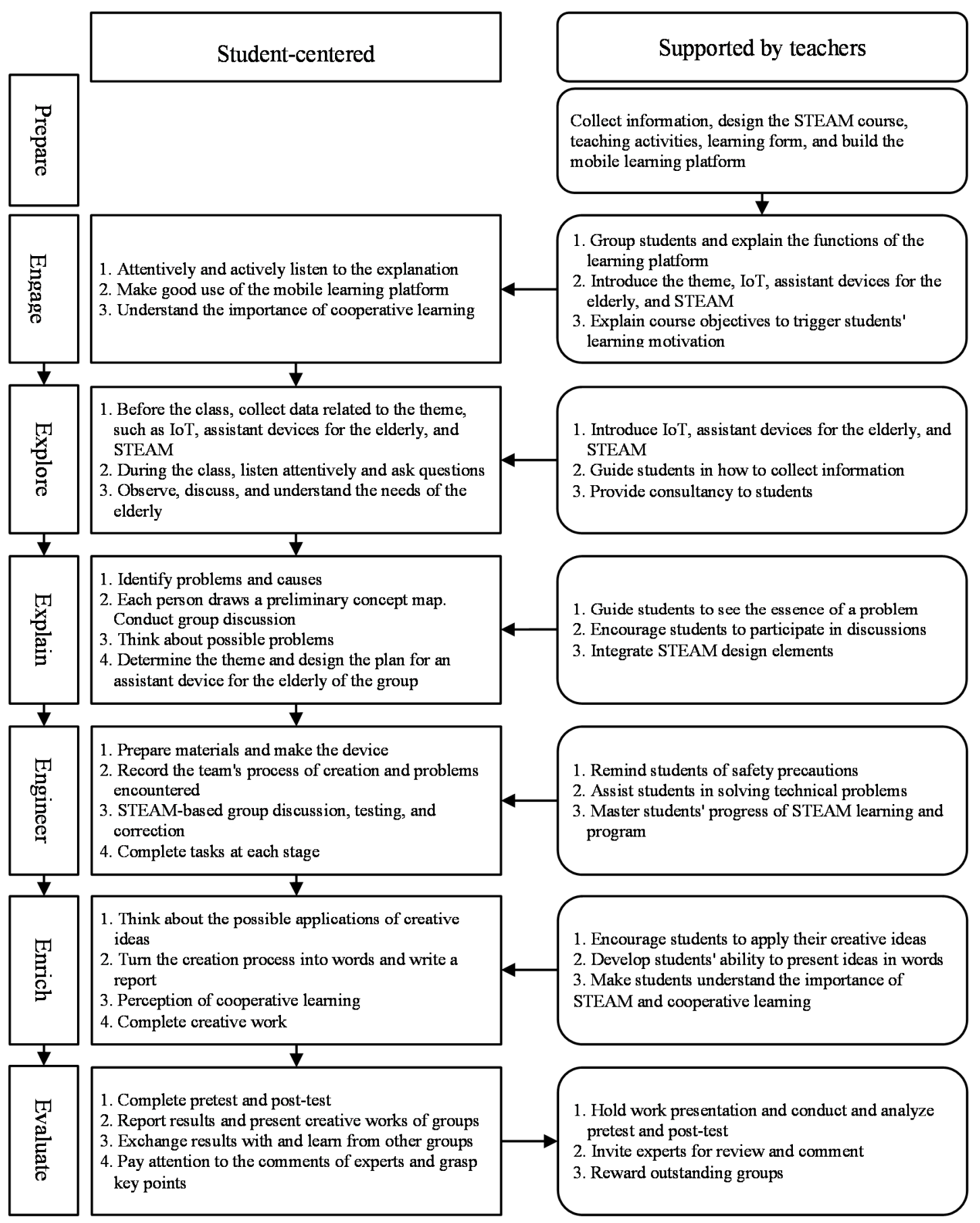

Figure 1. STEAM-6E teaching model for the creative design of Internet of Things (IoT) assistant devices for the elderly.

\section{Results and Discussion}

Based on the objectives and results, the analysis of the learning effectiveness of the students of the STEAM-6E course included an analysis of learning effectiveness and the learning process, which are described separately below. 


\subsection{Analysis of Students' Learning Effectiveness}

The 46 nursing majors attended the 15-week STEAM-6E course and filled in the questionnaire. This study analyzed the students' learning effectiveness in the STEAM course, 6E teaching, and thematic knowledge, as explained below in Table 3.

In terms of the STEAM course, the students' scores on learning effectiveness ranged from 4.07 to 4.19 points and indicated positive and significant differences, compared with the verification value of 3 points. The result implied that, after the STEAM- 6 E course, most students affirmed that they had learned STEAM interdisciplinary learning and integrative thinking and could integrate and apply knowledge from various disciplines and gain practical experience by combining theory and practice. Through the interpretation and hands-on experience of the STEAM-6E course, the students better understood scientific knowledge, reflected the relevant contents of scientific knowledge, and could efficiently achieve the effectiveness of interdisciplinary and integrative learning [6,7].

As for $6 \mathrm{E}$ teaching, the scores of the students on learning effectiveness ranged between 3.98 and 4.12 points and demonstrated positive and significant differences, compared with the verification value of 3 points. This shows that most students affirmed they had discussed ideas, conducted creative design, engaged in hands-on experiments, modification, and verification, completed work on assistant devices for the elderly, were guided to think about problems related to engineering, and learned how to observe and modify structural design. In addition, they had acquired practical experience in $6 \mathrm{E}$ (engagement, exploration, explanation, engineering, enrichment, and evaluation) [26].

With respect to thematic knowledge, the scores of the students on learning outcomes ranged between 4.05 and 4.21 points, indicating positive and significant differences, compared with the verification value of 3 points. This demonstrated that, after the STEAM- 6 E course, through hands-on processes, discussion, and analysis, most students gradually learned how to solve problems. In addition, they acquired knowledge of IoT and assistant devices for the elderly and practical experiences of integrating IoT into the creative design of those devices.

Table 3. Single-sample $t$-test analysis of learning effectiveness of students.

\begin{tabular}{|c|c|c|c|c|c|}
\hline Dimension & Item & Course Objective & Mean & S.D. & $t$ \\
\hline \multirow{6}{*}{ STEAM course } & $1-1$ & $\begin{array}{l}\text { Students can use life cases to illustrate } \\
\text { relevant scientific principles }\end{array}$ & 4.07 & 0.856 & $8.19^{* * *}$ \\
\hline & $1-2$ & $\begin{array}{l}\text { Students can apply scientific and } \\
\text { technological tools in creative design }\end{array}$ & 4.07 & 0.856 & $8.19 * * *$ \\
\hline & $1-3$ & $\begin{array}{l}\text { Students can complete the procedures of } \\
\text { creative work production }\end{array}$ & 4.12 & 0.851 & $8.60^{* * *}$ \\
\hline & $1-4$ & $\begin{array}{l}\text { Students can integrate a sense of beauty } \\
\text { in creative design }\end{array}$ & 4.19 & 0.795 & $9.79 * * *$ \\
\hline & $1-5$ & $\begin{array}{l}\text { Students can apply mathematical } \\
\text { calculations in production }\end{array}$ & 4.12 & 0.879 & $8.33^{* * *}$ \\
\hline & $1-6$ & $\begin{array}{l}\text { Students can apply STEAM integrative } \\
\text { thinking in learning }\end{array}$ & 4.14 & 0.915 & $8.17^{* * *}$ \\
\hline \multirow{6}{*}{$6 \mathrm{E}$ teaching } & $2-1$ & $\begin{array}{l}\text { Students are willing to actively engage in } \\
\text { course activities }\end{array}$ & 4.12 & 0.823 & $8.90 * * *$ \\
\hline & $2-2$ & Students can collect information & 4.12 & 0.823 & $8.90^{* * *}$ \\
\hline & $2-3$ & Students can discuss and analyze data & 4.12 & 0.823 & $8.90 * * *$ \\
\hline & $2-4$ & Students can make products & 4.12 & 0.793 & $9.23 * * *$ \\
\hline & $2-5$ & Students can apply basic knowledge & 4.05 & 0.872 & $7.87^{* * *}$ \\
\hline & $2-6$ & $\begin{array}{l}\text { Students gain experience in } \\
\text { self-examining their learning progress }\end{array}$ & 3.98 & 0.831 & $7.71^{* * *}$ \\
\hline
\end{tabular}


Table 3. Cont.

\begin{tabular}{lclccc}
\hline Dimension & Item & \multicolumn{1}{c}{ Course Objective } & Mean & S.D. & $t$ \\
\hline & $3-1$ & Students can learn about and develop IoT & 4.21 & 0.804 & $9.87^{* * *}$ \\
\cline { 2 - 6 } & $3-2$ & $\begin{array}{l}\text { Students can learn about and develop } \\
\text { assistant devices for the elderly }\end{array}$ & 4.07 & 0.884 & $7.94^{* * *}$ \\
\cline { 2 - 6 } $\begin{array}{l}\text { Thematic } \\
\text { knowledge }\end{array}$ & $3-3$ & $\begin{array}{l}\text { Students can gain practical experience of } \\
\text { IoT creative design }\end{array}$ & 4.07 & 0.799 & $8.78^{* * *}$ \\
\cline { 2 - 6 } & $3-4$ & $\begin{array}{l}\text { Students can gain practical experience of } \\
\text { the creative design of assistant devices for } \\
\text { the elderly }\end{array}$ & 4.09 & 0.811 & $8.84^{* * *}$ \\
\cline { 2 - 6 } & $3-5$ & $\begin{array}{l}\text { Students can incorporate IoT into the } \\
\text { creative design of assistant devices for } \\
\text { the elderly }\end{array}$ & 4.05 & 0.815 & $8.412^{* * *}$ \\
\hline
\end{tabular}

\subsection{Analysis of Learning Process of Students in the STEAM-6E Course}

The STEAM-6E special course on the creative design of IoT assistant devices for the elderly in this study took the $6 \mathrm{E}$ teaching model [24] as its main structure and planned the student-oriented $6 \mathrm{E}$ teaching model of the STEAM course. The students' works are summarized below. Based on the $6 \mathrm{E}$ procedures, the students' learning effectiveness in STEAM integrative knowledge, IoT, and creative design are discussed, analyzed, and summarized below:

(1) Engage: Explore real problems and the importance of STEAM integrative courses and stimulate students' motivation and willingness to engage

The most important factor affecting learning effectiveness is the degree of engagement of students. Therefore, it was of the utmost importance to increase the degree of engagement and learning motivation of this course. The teacher guided students to pay attention to current affairs through news reports, photos, and videos reflecting real-life problems, such as applications of IoT emerging technologies, aging trends, and long-term care 2.0. S0201: "From the videos shared by the teacher, we learned the trend of an aging society and the applications and development of IoT technologies." Furthermore, through questions and discussion, the teacher allowed the students to understand issues derived from events and triggered their motivation and interest to solve problems. S0502: "Most IT products are too complicated. Plus, with their deterioration in physical and mental functions (e.g., perception, cognition, and motor function), the elderly fail to understand and use such products." The teacher guided the students to link previous knowledge and learning experiences with the STEAM integrative course and explained the importance of the course, its objectives, and design procedures, and hoped to improve the students' abilities. S0303: "We regarded the needs and mental and physical functions of the elderly as the basis for the design of assistant devices for them. Then we adopted STEAM integrative thinking strategies to design IoT assistant devices that the elderly can easily operate." The mobile learning platform facilitated the students' learning of the main concepts of the course, previous knowledge, and contents to be learned, as well as group discussions and interactions between students and teachers, and this allowed the students to learn at ease.

(2) Explore: Cultivate students' ability in data collection and provide students with experience of STEAM integrative knowledge learning

The teacher needed to develop the students' abilities to collect information, construct knowledge, and acquire learning experiences and abilities to complete the course. According to the course plan, the teacher introduced IoT, assistant devices for the elderly, STEAM, and data collection methods. S0701: "We learned that IoT is applied in smart glasses, such as Google Glass and Sony's Single-Lens Display Module, after collecting information." Moreover, the teacher asked the students questions to guide their thinking about problems related to the theme and encouraged them to participate in discussions and 
group cooperative learning. S0104: "After our group discussion, we thought that what the elderly need the most includes products for presbyopia, radios, text translation, and smart navigation." The teacher observed the quality and conditions of the students' discussion and made the students aware of problems encountered by the elderly and their real needs as an important reference for the design of assistant devices for the elderly.

(3) Explain: Guide students to learn STEAM integrative thinking, deeply explore problems, and propose feasible solutions

The teacher guided the students in how to discuss and analyze the information collected to identify problems and real reasons. The teacher explained systematic concepts to the students, guided the students to think deeply by asking them questions, guided them to discuss and clarify concepts that were unclear and to learn the nature of problems, and ensured that the students could link what they learned with real situations. S0702: "After the guidance of our teacher, we decided to design a pair of multi-functional smart glasses so that the elderly can easily go where they want to go, see views clearly, and listen to radio broadcasts anytime, anywhere." The teacher encouraged students in groups to apply systematic concepts, principles, and theories. Each student was asked to draw a preliminary concept map to produce more creative ideas, such as the one shown in Figure 2. S0904: "We chose to recycle ice-cream sticks as the frame of the smart glasses, because they are easy to cut and turn into the product in our design drawing." Furthermore, students had group discussions about their ideas, thought about possible problems, required materials, and STEAM knowledge of the application site to develop the best possible solution and then determine their focus for assistant devices for the elderly.

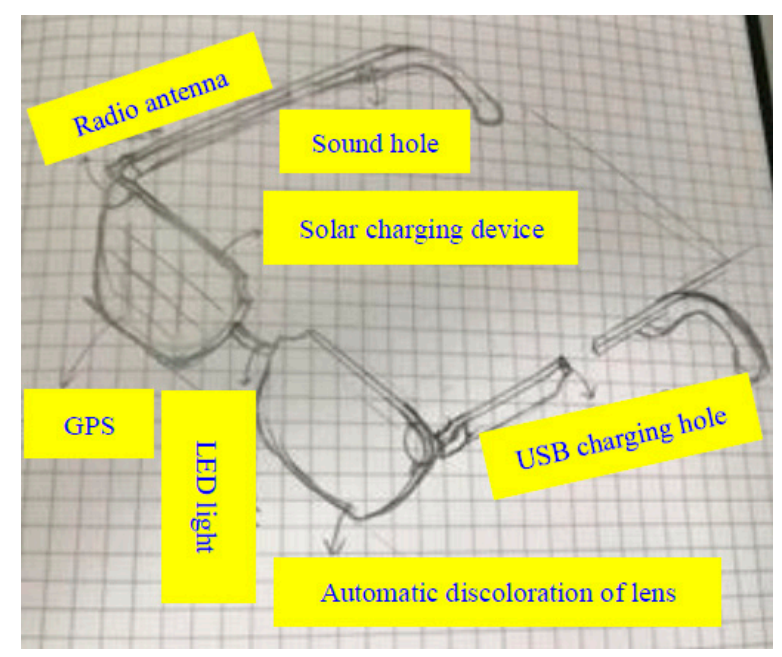

Figure 2. Students' design drawing of smart glasses for the elderly.

(4) Engineer/Extend/Elaborate: Students innovatively applied STEAM integrative knowledge to solve real problems and, in turn, gain a deeper understanding of that knowledge.

This was the hands-on stage. The teacher reminded the students of precautions, such as selection of materials, use of hand tools, and operation of processing equipment, to ensure that the students could complete their work safely, as shown in Figures 3 and 4 . Next, the teacher introduced the relevance between design and resources, guided the students to learn in creative design and exploration of STEAM knowledge, provided them with necessary assistance and technical guidance, and guided them in carrying out quality control and function tests. S0204: "Our teacher asked us to observe the daily life of the elderly to identify their potential needs. We should focus on problems, integrate STEAM knowledge to make suitable designs, and combine IoT and ICT to develop product prototypes." Moreover, the teacher grasped the students' learning and production progress by asking the students to record their creation 
process and problems encountered, and implemented STEAM discussion, testing, and correction to successfully complete tasks at each stage.

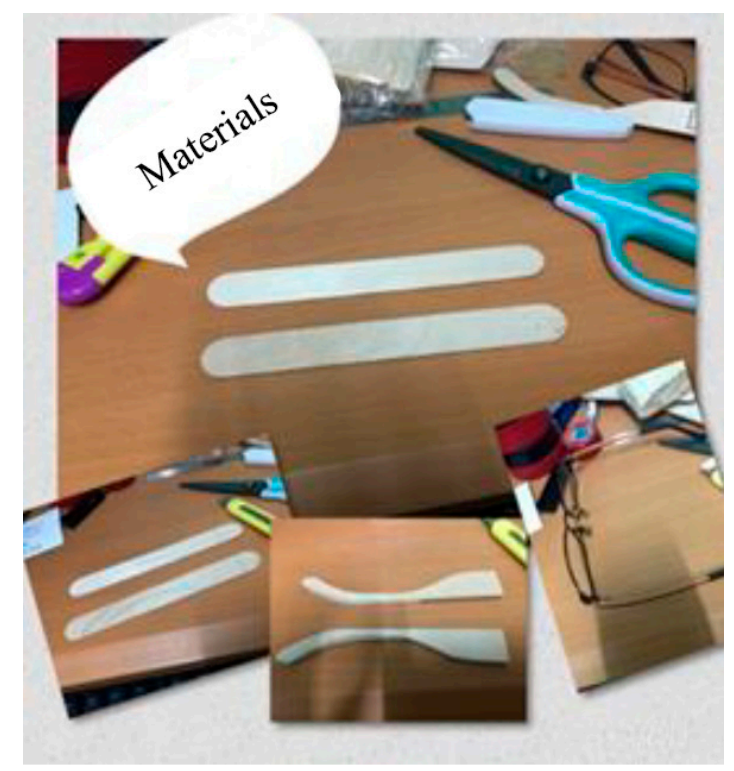

Figure 3. Drawing of materials, semi-finished products, and tools.
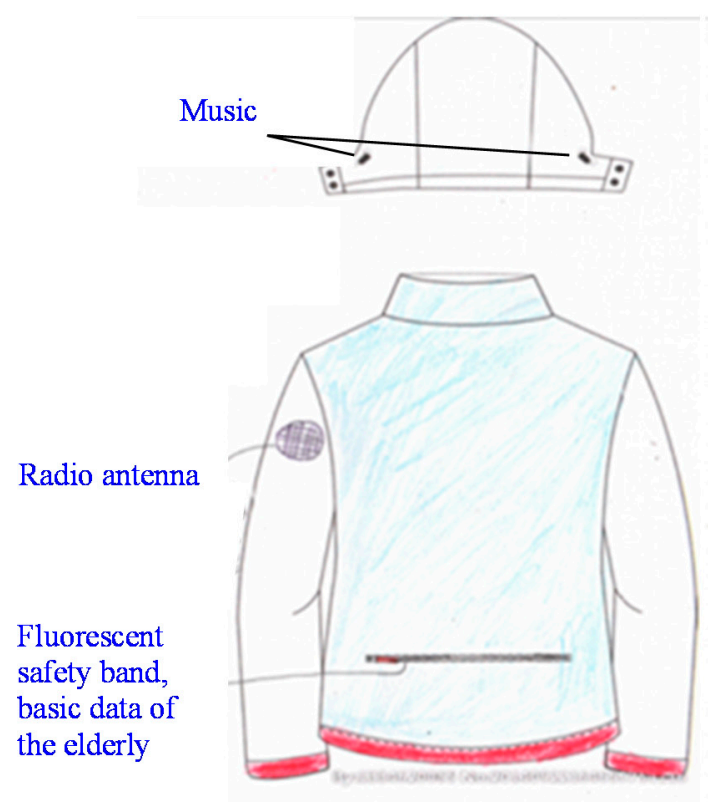

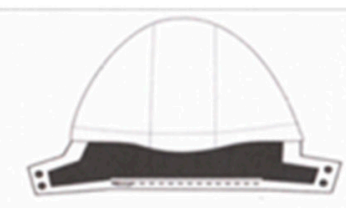

Built-in somatosensory adjustment and maintaining 25 to 27 degrees Celsius

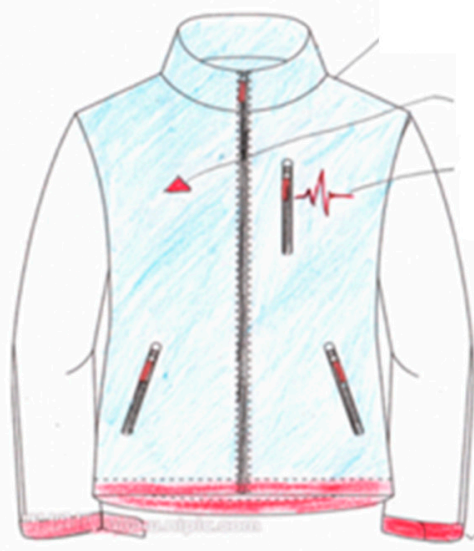

GPS positioning

Heartbeat sensor

Inductive distance drawstring

Figure 4. Students' drawing of multifunctional somatosensory clothes.

(5) Enrich: STEAM integrative knowledge was deepened and innovatively applied to solve more complex problems

Based on the original creative works, the teacher guided the students to extend the applications of their design concepts and made them aware that their STEAM knowledge could have wider applications, as shown in Figures 4 and 5. S0401: "We integrated and applied IoT emerging technologies, such as GPS, temperature sensors, heartbeat sensors, radio, and music, to meet the needs of the elderly." S0603: "During the production, we applied STEAM integrative thinking to successfully produce high-quality work." The students were asked to write down their creative ideas and creation process and write a report that 
included extended applications, engineering concepts, and feelings about group cooperative learning, as well as complete their work on time.
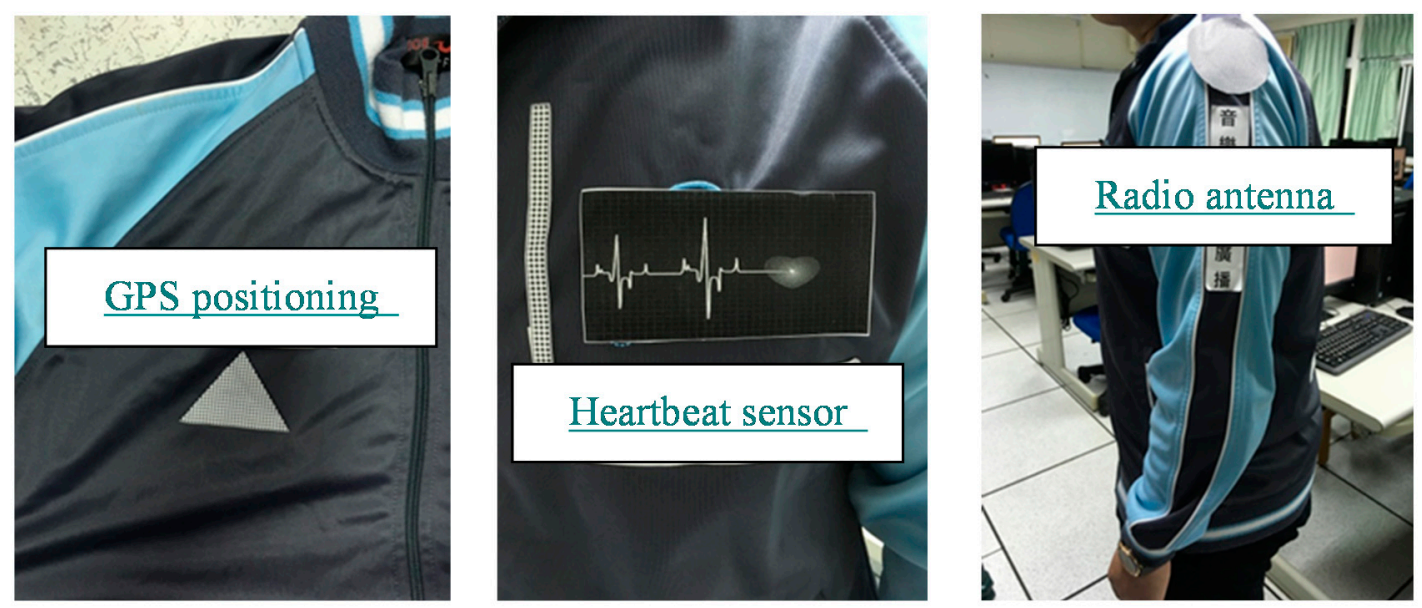

Figure 5. Students' multifunctional IoT somatosensory clothes.

(6) Evaluate: The teacher and the students were expected to learn the implementation status and learning effectiveness of the STEAM course as a reference for future improvement of course planning

The evaluation stage included assessments before, during, and after the course so that the teacher and the students could understand the learning outcomes. Before the course, the teacher made good use of a pretest to understand the learning needs and status of the students in order to adjust course contents and progress and confirm that the students would learn in line with the course objectives. During the course, the teacher asked the students to complete tasks in order at each stage so they could gage their learning status and progress and provide timely assistance. S0803: "Our teacher planned tasks for each unit. We were very tired and busy completing all the tasks. However, as we saw that our work was gradually completed, our efforts were worthwhile. We also understood the key points of the design of assistant devices for the elderly and possible applications of IoT." After the course, the teacher utilized a post-test to measure the effectiveness of the course. In addition, presentations of the results were held. Each group presented their creative work and design concept and exchanged with other groups. The students were expected to use engineering concepts on learning design, modeling, resources, and systems to solve problems and reach course objectives. S0102: "At the presentation, we presented our creative work and design concept. Also, we learned other groups' assistant devices and creative IoT applications." Furthermore, the experts were invited to comment on the works, select outstanding groups, distribute rewards, and encourage the students to carry out extended learning and research.

\subsection{Research Limitations}

This research is a preliminary study on the development and teaching design of a STEAM-6E course. It has the following limitations. It adopted purposive sampling and the quasi-experimental research method. In terms of the analysis of the implementation procedures and learning effectiveness of the STEAM-6E course, it is expected that there are aspects worth further exploring and correcting. Hence, it is not appropriate to overly interpret our research conclusions. Furthermore, the theme of this study is "creative design of IoT-based assistant devices for the elderly". The students aged between 19 and 20 years old in the Department of Nursing at the vocational college were expected to focus on learning the integrated design of IoT and assistant devices for the elderly. Therefore, they were able to present only conceptual and simulated works rather than physical products. Hence, future studies can probe into the specific assessment of a STEAM-6E course and relevant teaching experiments. 


\section{Conclusions and Suggestions}

This study aimed to integrate a STEAM integrative course and $6 \mathrm{E}$ teaching design to develop a STEAM-6E teaching model and promote STEAM education. In line with the discussion results of the focus interviews with the experts and the analysis of the experimental and teaching results onsite, the following conclusions and suggestions were reached.

\subsection{Conclusions}

(1) The STEAM-6E special course on the creative design of IoT assistant devices for the elderly included the three major aspects of the STEAM-6E course, the 6E teaching model, and thematic knowledge.

In light of the discussion results of focus interviews with the experts, it was determined that the key points of the STEAM-6E special course on the creative design of IoT assistant devices for the elderly must include three major aspects: the STEAM- $6 \mathrm{E}$ course, the $6 \mathrm{E}$ teaching model, and thematic knowledge. It also included 17 objectives to guide the students to learn STEAM's integrative knowledge, $6 \mathrm{E}$ implementation procedures, and knowledge related to the creative design of IoT assistant devices for the elderly.

(2) The nursing students at the vocational school affirmed the learning outcome from the STEAM-6E course, $6 \mathrm{E}$ teaching model, and thematic knowledge after attending the STEAM-6E course.

After the 15-week STEAM-6E course, most students deemed that their teacher's explanation and the hands-on course allowed them to better understand STEAM-related knowledge, acquire $6 \mathrm{E}$ practical experience, and acquire knowledge related to IoT and assistant devices for the elderly.

(3) The design of hands-on activity procedures of the STEAM-6E special course on the creative design of IoT assistant devices for the elderly enabled the students to learn the key points of the course step by step.

Through analysis of the students' STEAM-6E learning process, this study found that the students were highly interested in applying IoT emerging technologies in the production of assistant devices for the elderly. This course allowed the students to observe and consider the problems of their elderly family members in daily life as the basis of creative design and guided them to learn about the trends and applications of IoT emerging technologies. The cases related to the elderly and the scientific knowledge discussed during the courses aroused the students' sympathies. The teacher and the students exchanged and discussed information with each other, and the students truly became a part of the teaching and learning process.

(4) The STEAM-6E special course on the creative design of IoT-based assistant devices can strengthen students' abilities in the integration of STEAM knowledge and improve their learning effectiveness in each discipline.

This study combined the creative design of IoT-based assistant devices for the elderly with the teaching of a STEAM integrated course and conducted teaching and DIY (Do It Yourself) in the form of $6 \mathrm{E}$. With respect to knowledge and skills, through hands-on experience, the students learned about the correlation among IoT principles, design concepts of assistant devices, and the actual demands of the elderly. The students highly acknowledged the creative teaching of the STEAM-6E course, implying that the teaching activities derived from this study are worth further application.

(5) The STEAM-6E special course on the creative design of IoT-based assistant devices for the elderly improved the cooperative learning, professional knowledge, and confidence of the students.

For the STEAM-6E course, this study adopted cooperative learning by grouping students to help them integrate STEAM knowledge via hands-on experience. Moreover, via the 6E procedures, the students completed their creative design of IoT-based assistant devices for the elderly and consolidated their knowledge integration abilities. The STEAM-6E course is conducive to cultivating 
students' learning and development of knowledge in science, engineering, math, art, and technology and can help boost their confidence.

\subsection{Suggestions}

(1) The STEAM-6E special course on the creative design of IoT assistant devices for the elderly should include the three major aspects of the STEAM-6E course, the $6 \mathrm{E}$ teaching model, and thematic knowledge.

This study integrated STEAM integrative thinking into the STEAM-6E special course on the creative design of IoT assistant devices for the elderly and adopted the $6 \mathrm{E}$ teaching method. Therefore, the teacher should cover the contents of numerous disciplines while developing a STEAM-6E course. At the theme design stage, teachers of various disciplines could be invited for discussion. In line with the professionalism of the theme, appropriate teaching contents and activity procedures could be formulated.

(2) The implementation of a STEAM-6E course should be student-centered and supported by teachers.

This STEAM-6E course adopted PBL. During the course, the teacher guided the students to design, produce, test, modify, and complete works. At the end of the course, the teacher could guide the students toward professionalism and discuss the problems encountered by each group during creation so that the students might review their design, reflect on the knowledge learned, stimulate learning motivation, and give full play to the value of thematic teaching.

Author Contributions: Conceptualization, C.-C.C. and S.-J.L.; Methodology, C.-C.C.; Software, C.-L.L.; Validation, C.-C.C., S.-J.L., and Lin, C.L.; Formal Analysis, C.-C.C.; Investigation, C.-L.L.; Resources, C.-C.C.; Data Curation, C.-L.L.; Writing-Original Draft Preparation, C.-C.C.; Writing-Review and Editing, S.-J.L.; Visualization, S.-J.L.; Supervision, C.-C.C.; Project Administration, C.-C.C.; Funding Acquisition, S.-J.L.

Funding: This research was funded by Ministry of Science and Technology grant number MOST 106-2511-S-504-001.

Conflicts of Interest: The authors declare no conflict of interest.

\section{References}

1. Chu, T.K.; Tsui, D.H.; Peng, M.C.; Chen, S.T. An Overview of the Long-term Care Insurance Plan in Taiwan. J. Chang Gung Inst. Technol. 2015, 23, 1-14.

2. Yu, C.P. University Mergers and Integration in Europe. Tsing Hua J. Educ. Res. 2017, 34, 163-199.

3. Quigley, C.F.; Herro, D. "Finding the Joy in the Unknown": Implementation of STEAM Teaching Practices in Middle School Science and Math Classrooms. J. Sci. Educ. Technol. 2016, 25, 410-426. [CrossRef]

4. Fan, S.C.; Yu, K.C. Core Value and Implementation of the Science, Technology, Engineering, and Mathematics Curriculum in Technology Education. J. Res. Educ. Sci. 2016, 61, 153-183.

5. Debeş, G. Effects of STEM Education Seminars on Teachers in the Schools of North Cyprus. Eurasia J. Math. Sci. Technol. Educ. 2018, 14. [CrossRef]

6. Kim, D.; Bolger, M. Analysis of Korean elementary pre-service teachers' changing attitudes about integrated STEAM pedagogy through developing lesson plans. Int. J. Sci. Math. Edu. 2017, 15, 587-605. [CrossRef]

7. Bahrum, S.; Wahid, N.; Ibrahim, N. Integration of STEM education in Malaysian and why to STEAM. International. J. Acad. Res. Bus. Soc. Sci. 2017, 7, 645-654.

8. Yew, E.H.; Goh, K. Problem-based learning: An overview of its process and impact on learning. Health Prof. Educ. 2016, 2, 75-79. [CrossRef]

9. Phungsuk, R.; Viriyavejakul, C.; Ratanaolarn, T. Development of a problem-based learning model via a virtual learning environment. Kasetsart J. Soc. Sci. 2017, 38, 297-306. [CrossRef]

10. Burke, B.N. The ITEEA 6E Learning ByDesign ${ }^{\mathrm{TM}}$ Model: Maximizing Informed Design and Inquiry in the Integrative STEM Classroom. Technol. Eng. Teach. 2014, 73, 14-19.

11. Wu, F.; An, N.; Wu, Y.H. Development and Implementation for Elder Collaborative and Smart Community. J. Gerontechnol. Serv. Manag. 2016, 4, 29-42. 
12. Huang, E.W.; Chiou, S.F.; Pan, M.L.; Ku, C.K. A Review of Information and Communication Technologies for Long Term Care Applications. J. Long-Term Care 2012, 16, 219-235.

13. Yusif, S.; Soar, J.; Hafeez-Baig, A. Older people, assistive technologies, and the barriers to adoption: A systematic review. Int. J. Med. Inform. 2016, 94, 112-116. [CrossRef] [PubMed]

14. Liao, K.N.; Yang, H.F.; Lee, M.S. Applying the Concept of the Internet of Things in iPads to Improve Inpatient Consultation Time Efficiency. J. Healthc. Manag. 2015, 16, 345-358.

15. Park, E.; del Pobil, A.P.; Kwon, S.J. The Role of Internet of Things (IoT) in Smart Cities: Technology Roadmap-oriented Approaches. Sustainability 2018, 10, 1388. [CrossRef]

16. Zheng, R.; Zhang, M.; Zheng, Q.; Wu, Q.; Wei, W. Security Collaborative Optimization Strategy for Perception Layer in Cognitive IoT. J. Internet Technol. 2017, 18, 685-696.

17. Kim, T.H.; Ramos, C.; Mohammed, S. Smart city and IoT. Future Gener. Comput. Syst. 2017, 76, $159-162$. [CrossRef]

18. Kim, Y.; Moon, J.; Hwang, E. Constructing Differentiated Educational Materials Using Semantic Annotation for Sustainable Education in IoT Environments. Sustainability 2018, 10, 1296. [CrossRef]

19. Lou, S.J.; Tsai, H.Y.; Tseng, K.H. STEM Online Project-Based Collaborative Learning for Female High School Students. Kaohsiung Norm. Univ. J. Educ. Soc. Sci. 2011, 30, 41-61.

20. Ko, Y. A Study of the Hand Operating Thresholds during the Usage of an Electric Steam Iron by College Students. Eurasia J. Math. Sci. Technol. Educ. 2017, 13, 6325-6335. [CrossRef]

21. Choi, Y.; Lim, Y.; Son, D. A Semantic Network Analysis on the Recognition of STEAM by Middle School Students in South Korea. Eurasia J. Math. Sci. Technol. Educ. 2017, 13, 6457-6469. [CrossRef]

22. Chien, Y.H.; Chu, P.Y. The Different Learning Outcomes of High School and College Students on a 3D-Printing STEAM Engineering Design Curriculum. Int. J. Sci. Math. Educ. 2017, 18, 1-18. [CrossRef]

23. Park, H.; Byun, S.; Sim, J.; Han, H.; Baek, Y.S. Teachers' Perceptions and Practices of STEAM Education in South Korea. Eurasia J. Math. Sci. Technol. Educ. 2016, 12, 1739-1753.

24. Barry, N. The ITEEA 6E learning byDeSIGN ${ }^{\mathrm{TM}}$ Model. Technol. Eng. Teach. 2014, 73, 14-19.

25. Berg, P.O. Postmodern management? From facts to fiction in theory and practice. Scand. J. Manag. 1989, 5, 201-217. [CrossRef]

26. Chou, H.J.; Lin, H.C. Applying Virtual Reality Application with 6E Instructional Model in Living Technology at High School: A Case Study of Construction Design. J. Technol. Human Resour. Educ. 2018, 4, 67-89. 